\title{
A DESESTATIZAÇÃO DO SUS E A TRANSFERÊNCIÁ DA PROTEÇÃO SOCIAL GARANTIDA CONSTITUCIO- NALMENTE AO SETOR PRIVADO
}

\section{THE DESESTATIZATION OF SUS AND THE TRANS- FER OF CONSTITUTIONALLLY GUARANTEED SOCIAL PROTECTION TO THE PRIVATE SECTOR}

\author{
Pedro Ivo Biancardi Barboza' \\ DOI: https://doi.org/10.37767/2591-3476(2021)04
}

Fecha de envío: 19.07.2021

Fecha de aceptación: 16.09.2021

\section{RESUMEN:}

Este artigo objetiva analisar a figura do Estado prestador de serviços e a complementação dos serviços de saúde pelos entes privados. Por meio da pesquisa teórica, bibliográfica e documental empírica, busca-se analisar a proteção social e sua dependência da atuação estatal, considerando as mudanças ocorridas no desenvolvimento dos serviços de saúde mediante as contratualizações, tendo como problema central a dificuldade para se materializar o acesso universal e integral à saúde.

Ainda que o debate suscite sucessivas investigações, é possível verificar que modelos de maiores performances em termos de saúde são aqueles que consagram a universalização da saúde pública e nos quais a proteção social exerce papel crucial, o que demonstra que a saúde deve se expressar enquanto questão de Estado em seu aspecto estrutural, porém por meio de uma melhor governança sanitária entre público e privado na definição de prioridades e na prestação de serviços de saúde

\section{ABSTRACT}

This article aims to analyze the figure of the State providing services and the complementation of health services by private entities. Through theoretical, bibliographical and empirical documentary research, we seek to analyze social protection and its dependence on state action, considering the changes that have occurred in the development of health services through contracts, with the main problem being the difficulty to materialize access universal and integral to health.

Although the debate prompts successive investigations, it is possible to verify that models

1 Doutorando em Saúde Global e Sustentabilidade pela Universidade de São Paulo, Mestre em Ciências da Saúde pelo Instituto de Assistência Médica ao Servidor Público Estadual. E-mail: peivo_barboza@usp.com. ORCID iD: https://orcid.org/0000-0002-6932-368X. 
with the greatest performances in terms of health are those that enshrine the universalization of public health and in which social protection plays a crucial role, which demonstrates that health must be expressed as an issue structural aspect, however through better health governance between public and private in the definition of priorities and the provision of health services.

PALABRAS CLAVE: direito à saúde; Sistema universal de saúde; Administração Pública; Contratos.

KEY WORDS: Right to health; Universal health system; Public administration; Contracts.

\section{Introdução}

O contexto trazido pelo neoliberalismo, com as transformações para uma Administração Gerencial, implicou mudanças na natureza da gestão, com a premissa de que a lógica de mercado poderia diminuir os gastos públicos, aumentando a eficiência (Louvison, 2019:2). Observa-se que a maior desestatização da gestão e as parcerias com o setor privado e com o terceiro setor vêm invertendo aquilo que é universal ou complementar na assistência à saúde garantida por prestações positivas pelo Estado, tornando a fronteira entre o público e privado no Sistema Único de Saúde (SUS) num espaço acirrado, com implicações ao funcionamento do sistema e à efetividade do direito à saúde garantido constitucionalmente.

Segundo Yarid (2009:47), apesar da antinomia Estado/mercado, é possível notar que os dilemas da saúde possuem um ponto central, qual seja, a capacidade de efetivamente enfrentar a desigualdade e exclusão sociais, com a prevalência do interesse público na condução política do Estado e com a introdução de mecanismos reais de controle social sobre os serviços de saúde estatais ou privados. Lembremo-nos que o Estado atua sem o fito de lucro no âmbito público.

Desse modo, pretendemos com este artigo analisar a figura do Estado prestador de serviços e a complementação dos serviços de saúde pelos entes privados.

Primeiramente, iremos contextualizar a proteção à saúde na ordem constitucional brasileira, que positivou os direitos sociais e, por via de consequência, o direito à saúde, mediante prestações positivas a serem oferecidas pelo Estado. Para tanto, nos utilizamos da pesquisa bibliográfica e teórica a fim verificar o papel do Estado e da Administração Pública na efetivação do direito fundamental à saúde, positivado na Constituição Federal desde 1988, bem como nas mudanças da provisão dos serviços de saúde que pode se dar por entes privados aproveitando-se da dualidade constitucional da prestação.

A seguir, trataremos da subsidiariedade da provisão de serviços de saúde pelos entes privados e do terceiro setor, a partir daquilo que chamamos de contratualizações (Oliveira, 2008:43-44). Nesse sentido, realizamos pesquisa documental empírica por intermédio de consulta aos registros contratuais oficiais existentes nos Portais da Transparência sobre a prestação de serviços de saúde. Consultamos também o Global Health Expenditure Database (GHED), da Organização Mundial da Saúde (OMS), para verificar, de forma comparativa, o investimento público na prestação privada em saúde no Brasil e em países que possuem sistema universal de saúde, para verificar a despesa total com saúde 
pública e o gasto per capita em saúde.

Após, procuramos traçar as implicações dessas alterações na forma de prestação dos serviços de saúde em termos de eficiência, e analisar a permeabilidade entre o Estado e os atores societais no cumprimento do direito à saúde, tendo por base o caráter dual constitucional do sistema de saúde brasileiro.

Por fim, apresentamos nossas conclusões sobre subsidiariedade do privado nos serviços de saúde em detrimento da prestação direta estatal.

\section{A constitucionalização do direito à saúde na Constituição Federal brasileira}

De acordo com Barroso (2005:11), o neoconstitucionalismo ou novo direito constitucional voltado para resultados trouxe um conjunto amplo de transformações no Estado e no direito constitucional para incluir força normativa da Constituição, por meio da expansão da jurisdição constitucional e do desenvolvimento de uma nova dogmática da interpretação constitucional. Desse conjunto de fenômenos resultou um processo extenso e profundo de constitucionalização do Direito.

Para o citado autor, a constitucionalização do Direito proporcionou um efeito expansivo das normas constitucionais, cujo conteúdo material e também axiológico passou a ser irradiado com força normativa por todo o sistema jurídico, dotadas de imperatividade, aptas a permitir a deflagação de mecanismos próprios de coação e de cumprimento forçado em caso de sua inobservância..

Por sua vez, a positivação dos direitos sociais no âmbito da Constituição brasileira demonstrou a preocupação com o desenvolvimento da sociedade e com a valorização dos indivíduos socialmente inferiorizados, tornando a postura do Estado mais intervencionista, como agente do desenvolvimento e da justiça social (Sundfeld, 2010:55).

Consagra-se uma maior intervenção do Poder Estatal para reparar as condições materiais de existência dos contingentes populacionais mediante políticas públicas e fez emergir essa classe de "direitos", cuja tutela parecia não existir e que experimentou incontestável expansão e até mesmo institucionalização.

Conforme Silva (2010:286), essa afirmação dos direitos sociais, enquanto dimensão dos direitos fundamentais do homem,configuram prestações positivas pelo Estado, direta ou indiretamente, enunciadas em normas constitucionais com vistas a igualização de situações desiguais. Vem consubstanciado em normas programáticas pela Constituição Federal, as quais estabelecem programas a serem alcançados pelos governos com vistas à realização de objetivos de justiça social e a consecução do bem-estar social geral e o desenvolvimento da personalidade humana.

E, a partir do paradigma neoconstitucionalista, que consagra o prestígio adquirido pelos princípios dentro da dinâmica do Estado Democrático de Direito e a construção de um referencial teórico capaz de afirmar a eficácia positiva desse tipo normativo, ultrapassouse a "programaticidade" das normas de direitos sociais e afirmou-se também sua juridicidade. ${ }^{2}$

2 Sobre o assunto, ver: Neoconstitucionalismo e constitucionalização do Direito (O triunfo tardio do direito constitucional no Brasil) (2005). Revista de Direito Administrativo, Rio de Janeiro, v. 240, p. 1-42. Disponível em: http://bibliotecadigital.fgv.br/ojs/index.php/rda/article/view/43618.. 
O direito a saúde passa ser considerado "direito de todos e dever do Estado", garantido mediante políticas sociais e econômicas que visem à redução do risco de doença e de outros agravos, e acesso universal, gratuito e igualitário às ações e serviços de saúde, nos termos previstos nos artigos 196 a 200 da Constituição Federal.

Tais obrigações advêm de sua natureza, já que o direito à saúde, como um direito individual e pessoal, é considerado fundamental e também social, podendo ser aplicado, pelo Judiciário, nos termos dos arts. $5^{\circ}$, inciso XXXV, e 196 da Constituição Federal.

Disso decorre que, como direito fundamental, atribui ao Estado o encargo de atuar para a garantia de sua promoção, proteção e recuperação, o que requer uma Administração Pública organizada para a prestação de ações e serviços de saúde, assim como para regulamentação, fiscalização e controle das atividades no âmbito sanitário, pouco importando se executadas diretamente ou pela iniciativa privada.

\section{A subsidiariedade do privado na prestação de serviços de saúde}

O sistema público universal brasileiro integra cuidados individuais e ações coletivas de prevenção e promoção, com enfoque populacional que exige políticas transversais intersetoriais para enfrentar os determinantes sociais da saúde pelo Estado. Adota assim uma concepção de cidadania plena(Giovanella et al., 2018:1775), com predomínio da administração e prestação públicas de melhor qualidade, menores custos e maior eficiência, e de sua maior intervenção como provedor e financiador de serviços por meio da arrecadação fiscal ou de contribuições sociais (Scheffer e Aith, 2016:356).

O Sistema Único de Saúde (SUS) está organizado numa rede de ações e serviços públicos de saúde interfederativa, regionalizada e hierarquizada, constituída por serviços da União, dos Estados, do Distrito Federal e dos Municípios, em cumprimento ao princípio da descentralização. É também regido pelos princípios da universalidade, da igualdade e do atendimento integral, e guiado pelas diretrizes constitucionais da descentralização (política e administrativa), da integralidade de atendimento, que possui natureza híbrida de princípio e uma diretriz do SUS (Aith et al. 2014:12) (12) conforme previsto tanto na Constituição Federal como na Lei n. 8.080, de 19 de setembro de 1990³ , e da participação da comunidade na sua gestão.

Tem, ainda, com um dos vetores que o conformam e o impulsionam a equidade, ou seja, o tratamento diferente aos desiguais, oferecendo mais a quem precisa mais.

Para Ocké-Reis e Sophia (2009:74), o SUS proporcionou, assim, um fortalecimento da esfera pública, o acesso da população aos serviços médico-assistenciais e a melhoria das condições de saúde. Considerando que a assistência à saúde é um dever do Estado e um direito do cidadão conforme a Constituição, combina programas seletivos capazes de atender os grupos vulneráveis de forma universal.Diferentemente do que ocorre com a ordem econômica na Constituição Federal brasileira, em que o caráter de subsidiariedade do Estado fica mais claro na prestação direta de atividades econômicas, a situação se inverte na questão social, pois a Constituição é clara ao responsabilizar o Estado como um ator importante - e talvez principal, na educação, saúde e assistência social, a ordem social tratada a partir do artigo 193 da Constituição Federal objetiva o bem-estar e a justiça social, deixando claro o caráter social da Constituição Federal (Violin, 2015:209-210).

\footnotetext{
3 Brasil. Lei n. 8.080, de 19 de setembro de 1990. Dispõe sobre as condições para a promoção, proteção e recuperação da saúde, a organização e o funcionamento dos serviços correspondentes e dá outras providências. Diário Oficial da União, Brasília, DF, 20 set. 1990, p. 018055. Disponível em: http:// www.planalto.gov.br/ccivil_03/leis/L8080.htm..
} 
Mas o sério problema no acesso à saúde acabou por culminar com a superposição de vantagens ou mesmo de desvantagens das políticas públicas de Estado sobre as mesmas categorias de indivíduos. Tal realidade reflete-se na insatisfação dos cidadãos com a prestação de serviços públicos na área da saúde, claramente demonstrada pela quantidade de ações judiciais demandando serviços de saúde no Brasil, despeito da igualdade e equidade no tratamento objeto do artigo 198 da Constituição Federal.

Não restam dúvidas de que novos paradigmas para a gestão pública de serviços de saúde precisam existir. Não se deve descartar aspectos importantes do mundo empresarial que podem inovar a Administração Pública, desde que princípios públicos como a participação comunitária, a transparência administrativa, a impessoalidade, a intersetorialidade sejam a eles associados, "amarrando" as políticas públicas e a capacidade de planejamento de ações que levem em conta as diferentes dimensões da vida social (Santos, 2010:84).

Para atingir os objetivos estampados no capítulo da saúde, a Constituição Federal deu amparo também à participação das instituições privadas em caráter complementar no Sistema Único de Saúde (SUS), o que acabou por fomentar a maior desestatização da gestão e as parcerias com o setor privado e com o terceiro setor. Isso ocasionou, porém, uma inversão daquilo que é universal ou complementar na assistência à saúde prevista como um direito fundamental e garantida por prestações positivas pelo Estado.

Consagra-se um caráter dual ao sistema de saúde brasileiro, ou seja, a política de saúde incorpora formalmente a assistência privada não só de maneira complementar, há uma distinção entre uma esfera pública de prestação de serviços de saúde (o SUS), prevista no artigo 198 da Constituição Federal, e uma esfera livre à iniciativa privada para prestação

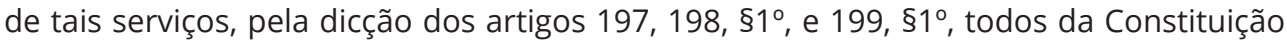
Federal. Ou seja, não mais considera a prestação desses serviços como prerrogativa exclusiva estatal, já que o mesmo arcabouço jurídico do sistema público e universal de saúde preserva a liberdade da iniciativa privada.

Fomentam-se então as contratualizações e a Administração Pública dão maior abertura à consensualidade como um efetivo instrumento de realização das finalidades públicas, na busca de resultados concretos satisfatórios ao desenvolvimento econômico-social (Palma, 2015:126). Nesse novo modo de agir administrativo, o parceiro privado deve participar com o ente administrativo da construção da decisão administrativa e o controle exercido sendo o controle exercido pelo primeiro somente resultados.

Por essa razão, os acordos são desejáveis, daí porque surgiram novas formas de pactuação com os órgãos da Administração Pública e com a iniciativa privada, oxigenando a capacidade de gestão e implementação de políticas públicas do Estado.

Com isso, o conceito de administração por objetivos passa a ser mais bem atendido com a aplicação de novas técnicas de descentralização e de delegação, que contribui para a existência de regramentos mais flexíveis e adequados aos fenômenos setoriais a que se dirigem. Não mais basta que o Estado se submeta ao Direito conformado pelas leis, que é seu próprio produto: é necessário que estas leis se submetam ao Direito, que é produto da sociedade. 
Nesse cenário é que surgem os contratos de gestão, acordos administrativos organizatórios ou colaborativos, os primeiros firmados na qualidade de instrumentos de coordenação para interligação de diferentes órgãos e entidades da própria Administração Pública, e os segundos firmados com o particular, constituindo a chamada relação público-privada (Oliveira 2008:266).

Recurso de índole consensual a ser aplicado no âmbito das relações administrativas, os contratos de gestão tiveram como objetivo incrementar o desempenho dos órgãos e entidades, com finalidade de assegurar uma atuação que Ihes confira maior autonomia de gestão e também instituir na Administração Pública a programação prévia de suas atividades, com a estipulação de mecanismos de controle dos resultados eventualmente aferidos.

De acordo com Binenbojm (2008), criaram-se filhotes híbridos oriundos da dicotomia entre gestão pública e gestão privada (pública ou publicizada), multiplicando as modalidades participativas seja entre instâncias de governo entre si, seja com entidades privadas ou do terceiro setor, que passam a ser sócias na promoção do desenvolvimento econômico e social, por meio da descentralização de serviços a organizações mais flexíveis (o que se vê também no campo da saúde). Atualmente, o Brasil conta doze tipos de pessoas jurídicas prestadoras de serviços públicos de saúde no campo assistencial ${ }^{4}$ por meio de contratos de gestão.

Todavia, percebemos uma maior prevalência das organizações sociais, "pessoas jurídicas de direito privado, sem fins lucrativos, cujas atividades sejam dirigidas ao ensino, à pesquisa científica, ao desenvolvimento tecnológico, à proteção e preservação do meio ambiente, à cultura e à saúde", conforme art. $1^{\circ}$ da Lei n. 9.637, de 15 de maio de $1998^{5}$.

Tal modalidade, também adstrita aos ditames da Lei de Responsabilidade Fiscal (LRF), constitui-se numa forma de flexibilização assumida pela Administração Pública, com grande adesão dos gestores estaduais e municipais de saúde em todo o país. Tal adoção encontra amparo no Acórdão exarado pelo Supremo Tribunal Federal no âmbito da ADI 1923/DF6.

Ademais, o Acórdão 2444/16-TCU7 , do Tribunal de Contas da União (TCU), fortaleceu a contratação por meio de OSs., em especial por conta do limite de pessoal, pois entendeu que somente o gasto com terceirização de mão de obra que se referir a substituição de servidores e empregados públicos deve fazer parte do cálculo dos limites de despesa com pessoal prevista no art. $18, \S 1^{\circ}$, da LRF.Assim, no caso das OSs., observamos que possuem limites de contratação de pessoal maiores do que os estabelecidos na LRF $(70 \%$

\footnotetext{
4 São elas: AUT - Autarquia, FEDP - Fundação Pública/Fundação Estatal de Direito Público, SEM - Sociedade de Economia Mista, EP - Empresa Pública, CP - Consórcio Público, FPA - Fundação Privada de Apoio, SSA - Serviço Social Autônomo, OS - Organização Social, OSCIP - Organização Social Civil de Interesse Público, PPP - Parceria Público-Privada, CHPUBL - Chamada Pública, EFB - Entidade Filantrópica ou Beneficente.

5 Brasil.Lei n. 9.637, de 15 de maio de 1998. Dispõe sobre a qualificação de entidades como organizações sociais, a criação do Programa Nacional de Publicização, a extinção dos órgãos e entidades que menciona e a absorção de suas atividades por organizações sociais, e dá outras providências. Diário Oficial da União. Brasília, DF, 18 mai.1998, p. 8, Seção 1, retificado em 25 mai. 1998, p. 1, Seção 1. Disponível em: http://www.planalto.gov.br/ccivil_03/ leis/19637.htm

6 Brasil. Supremo Tribunal Federal. Ação Direta de Inconstitucionalidade 1923. Ministro Relator: Ayres Brito. Ata no 193/2015.Brasília, DF, 17 dez.2015, nº 254, p. 30-31. Disponível em: http://portal.stf.jus.br/processos/detalhe.asp?incidente=1739668. Acesso em: 23 set. 2020.

7 BRASIL. Tribunal de Contas da União. Acórdão 2444/2016 - TCU. Plenário. TC-23.410/2016-7. Solicitação do Congresso Nacional. Rel. Bruno Dantas. $\operatorname{Ata~}^{\circ}$ 36, de 21 de setembro de 2016. Data da Sessão: 21/09/2016. Diário Oficial da União. Brasília, DF, 30 set. 2016, Seção 1, p. 150. Disponível em: http:// www.in.gov.br/materia/-/asset_publisher/Kujrw0TZC2Mb/content/id/24209460/do1-2016-09-30-ata-n-36-de-21-de-setembro-de-2016-24208568. Acesso em: 24 jun.2020.
} 
ou $80 \%$ das despesas de custeio, conforme sejam, unidade hospitalar ou ambulatorial, respectivamente), já que somente o gasto com terceirização de mão de obra que se referir a substituição de servidores e empregados públicos deve fazer parte do cálculo dos limites de despesa com pessoal previsto no art. $18, \S 1^{\circ}$, da LRF, o que não se aplica às OSs.

Mas, em que pese o caráter dual do sistema trazido pelos arts. 197 e seguintes da Constituição Federal (Meniccucci, 2007:75-76) , a incorporação de princípios do setor privado no setor público, hoje fortemente induzido por metas produtivistas, gerou uma mercantilização explícita da saúde, além de apontar para um efeito reducionista na produção do cuidado em redes. Sem contar o fato de que não possuímos avaliações comparativas ou comprovações científicas de que tais mudanças tenham trazido menor custo e maior efetividade ao sistema de saúde brasileiro.

A rigor, essa privatização tem sido também responsável por um quadro de desfinanciamento crônico do SUS, que tem dificultado o asseguramento do direito à saúde pelo Estado e o cumprimento das regras de custeio, estimulando a consolidação da lógica mercantil e de interesses capitalistas no setor da saúde, as quais contaminam o SUS e ameaçam sua base de sustentação política.

A realidade brasileira aponta para constantes restrições do gasto público, dos gastos catastróficos com bens e serviços de saúde e dos desembolsos diretos, conforme disposto na EC $n^{\circ} 86 / 15^{8}$ e na EC n ${ }^{\circ} 95 / 16^{9}$, torna-se cada vez maior redução do papel do governo na criação de mecanismos voltados para a proteção financeira das famílias e dos trabalhadores, com risco de empobrecimento dos indivíduos e desvirtuamento da integralidade da atenção conforme suas necessidades e independentemente de mérito ou renda.

De outro lado, não possuímos uma noção de governança, primordial para essa passagem de um modelo centrado no Estado para um modelo colaborativo. Com efeito, a governança sanitária deve ser entendida sob o espeque das configurações do mix públicoprivado da provisão de serviços, em geral expressados pelo modo como processos de reforma do Estado e do sistema de saúde promoveram a redistribuição de funções entre entes governamentais e privados no território brasileiro (Lima et al. 2019:1).

Ou seja, a governança sanitária deve ser coproduzida por uma ampla gama de participantes ao nível estatal (ministérios, parlamentos, agências, organismos e comissões) e social (empresas, cidadãos, grupos comunitários, as mídias global e social em rede e fundações) (Kickbusch e Gleicher, 2012:3), e deve estabelecer um modus operandi nas políticas governamentais que envolvam questões ligadas ao formato político-institucional do processo decisório, a definição do 'mix' apropriado de financiamento de políticas, ao alcance geral dos programas, a aspectos gerenciais e administrativos do Estado e padrões de articulação e cooperação entre atores sociais e políticos (Buss et al., 2012:1480).

Tais fatos podem jogar por terra a própria noção de saúde enquanto direito fundamental, inerente à condição de cidadania.

\footnotetext{
8 Brasil. Emenda Constitucional nº 86, de 17 de março de 2015. Altera os arts. 165, 166 e 198 da Constituição Federal, para tornar obrigatória a execução da programação orçamentária que especifica. Diário Oficial da União, Brasília, DF, 18 mar. 2015, Seção 1, p 1. Disponível em: http://www.planalto.gov.br/ ccivil_03/constituicao/Emendas/Emc/emc86.htm.

9 BRASIL. Emenda Constitucional n 95, de 15 de dezembro de 2016. Altera o Ato das Disposições Constitucionais Transitórias, para instituir o Novo Regime Fiscal, e dá outras providências. Diário Oficial da União, Brasília, DF, 16 dez. 2016, Seção 1, p 2. Disponível em: http://www.planalto.gov.br/ ccivil_03/constituicao/Emendas/Emc/emc95.htm.
} 


\section{As implicações da permeabilidade público e privado e o direito à saúde}

Essa privatização e o "abandono" do ideal de um sistema público oriundos da permeabilidade entre atores societais e Estado tem sido motivo de constantes debates sob a ótica do caráter dual da prestação de serviços de saúde no Brasil.

Para a corrente estatista, o domínio privado ocupa funções de Estado, subtrai a natureza pública do SUS e nega o direito social de assistência à saúde, assegurado pela Constituição de 1988 (Ocké-Reis e Sophia, 2009:72), sendo, assim, necessária uma mediação política para frear a mercantilização do sistema de saúde brasileiro ${ }^{10}$. Segundo seus defensores, a atuação da Administração Pública, em especial por meio de relações de cooperação com entes do terceiro setor e privados que "acomodam" a dicotomia público/ privado, busca somente fugir matriz jurídico-administrativa constitucional, que consagra a necessidade de licitação e de concurso público, bem como limitações à contratação de pessoal impostas pela Lei de Responsabilidade Fiscal (LRF.

Em sentido oposto, a corrente privatista defende diferentes formas participativas que ligam os poderes públicos com o setor privado e associações da sociedade civil, dada maior autonomia em face do Estado para perseguir suas finalidades específicas. O privado aliviaria o público de uma carga desnecessária, pois é mais eficiente, possui processos de trabalho melhor estruturados, melhores instrumentos de avaliação e maior capacidade e velocidade para fomentar inovação.

Fato é que o direito a saúde, como direito à cidadania, exige que as políticas econômicas e sociais contem com uma maior intervenção do Estado, como provedor e financiador de serviços, por meio da arrecadação fiscal ou de contribuições sociais. Porém, o sistema foi afetado pela forma publicista de cunho neoliberal ${ }^{11}$, que restringiu o rol de atividades estatais e redefiniu o papel do Estado, cuja atuação passou a ser subsidiária aproveitandose da sistemática constitucional que traz a participação privada de forma complementar no SUS, reduzindo os recursos destinados ao setor da saúde.

Mas, mesmo que os contratos de gestão tenham ampliado de forma expressiva o acesso dos cidadãos brasileiros ao SUS, por levar a assistência a locais onde as pessoas não contavam com nenhum serviço de saúde com maior eficiência, produtividade e menor custo para os cofres públicos, não encontramos qualquer avaliação relativa ao custo e efetividade que demonstre que os hospitais e ambulatórios administrados por exemplo pelas OSs. apresentam, de forma geral, melhor produtividade do que os hospitais geridos pela Administração Pública Direta.

As informações dos Portais da Transparência disponíveis demonstram apenas dados de repasses financeiros, conforme pesquisa realizada neste trabalho. O Poder Público adota somente o critério financeiro para verificar os impactos da descentralização de serviços de saúde, vemos que participação do ente público no custeio e investimento para manutenção dos serviços prestados no período entre 2015 e 2019 é alta, com altos repasses

\footnotetext{
10 Para Ocké-Reis (2010, p. 102), a mercantilização do SUS consiste no descaso administrativo do ressarcimento, da generalização ilegal do copagamento, da existência de tabelas de pagamento descolada dos custos, da destinação de leitos públicos para o mercado, da apropriação particular dos hospitais universitários e da desigualdade no acesso ao SUS pela clientela da medicina privada, em contexto de medicalização da sociedade e do consumismo desenfreado de bens, serviços e tecnologias.

11 Ver: Brasil. Emenda Constitucional n 19, de 04 de junho de 1998. Modifica o regime e dispõe sobre princípios e normas da Administração Pública, servidores e agentes políticos, controle de despesas e finanças públicas e custeio de atividades a cargo do Distrito Federal, e dá outras providências. Diário Oficial da União, Brasília, DF, 5 jun. 1998, Seção 1, p. 1. Disponível em: http://www.planalto.gov.br/ccivil_03/Constituicao/Emendas/Emc/emc19.htm.
} 
para entidades privadas, conforme valores pagos pelo estado de São Paulo, adotado como exemplo, por instrumento jurídico e por tipo jurídico dos entes contratados:

\begin{tabular}{|c|c|c|c|c|c|c|}
\hline Instrumerto & 2015 & 2016 & 2017 & 2018 & 2019 & TOTAL \\
\hline $\begin{array}{l}\text { Contratos de Gestão- } \\
\text { Entidades Priv adas }\end{array}$ & $2.712 .300,00$ & $2.892 .000,00$ & $3.333 .700,00$ & $3.557 .500,00$ & $3.846 .800,00$ & $16.342 .300,00$ \\
\hline $\begin{array}{c}\text { Contratos de Gestão - } \\
\text { Autarquins }\end{array}$ & $162.000,00$ & $173,900,00$ & $192.400,00$ & $231.700,00$ & $249.600,00$ & $835.700,00$ \\
\hline $\begin{array}{c}\text { Contratos de Gestĩo- } \\
\text { Consórcios Públicos }\end{array}$ & $86.400,00$ & $92.400,00$ & $92.200,00$ & $100.600,00$ & $97.300,00$ & $468.900,00$ \\
\hline $\begin{array}{c}\text { Contratos de Gestão- } \\
\text { Fundações }\end{array}$ & $758.100,00$ & $1.018 .600,00$ & $1.061 .100,00$ & $1.018 .000,00$ & $1.079 .900,00$ & $4.935 .700,00$ \\
\hline $\begin{array}{l}\text { Contratos de Gestĩo- } \\
\text { Santas Casas }\end{array}$ & $110.500,00$ & $151.800,00$ & $182.500,00$ & $205.000,00$ & $296.700,00$ & $946.500,00$ \\
\hline
\end{tabular}

Tabela 1. Valores pagos para Gestão de Hospitais e Serviços de Saúde por Instrumento Jurídico - Custeio e Investimento - Contratos de Gestão

Fonte: Portal Financeiro do Gestor - CGOF/SES - 13 abr.2020. Disponível em: http://www.portalfinanceirodogestor.saude.sp.gov.brl. Adaptada pelo autor.

Nota: *Foram considerados apenas os valores efetivamente pagos

Em relação aos hospitais e ambulatórios sob o domínio público em São Paulo, temos:

\begin{tabular}{|l|l|l|l|l|}
\hline \multicolumn{2}{|l|}{ Despesas } & Custeio & Investimento & Total \\
\hline Ano & Pessoal & $789.809 .288,00$ & $2.777 .828,00$ & $\mathbf{2 . 8 1 1 . 8 0 4 . 5 3 5 , 0 0}$ \\
\hline $\mathbf{2 0 1 5}$ & $2.041 .462 .749,00$ & & & $\mathbf{2 . 7 9 6 . 4 0 5 . 0 5 2 , 0 0}$ \\
\hline $\mathbf{2 0 1 6}$ & $1.869 .492 .967,00$ & $926.912 .086,00$ & 0 & $\mathbf{3 . 0 0 6 . 1 0 3 . 7 1 7 , 0 0}$ \\
\hline $\mathbf{2 0 1 7}$ & $1.931 .914 .550,00$ & $1.068 .219 .032,00$ & $5.970 .134,00$ & $\mathbf{2 . 8 5 0 . 3 7 1 . 4 1 9 , 0 0}$ \\
\hline $\mathbf{2 0 1 8}$ & $1.929 .358 .005,00$ & $921.013 .414,00$ & $1.121 .406,00$ & \\
\hline $\mathbf{2 0 1 9}$ & $618.030 .604,00$ & $338.126 .226,00$ & $2.289 .204,00$ & $\mathbf{9 5 8 . 4 4 6 . 0 2 9 , 0 0}$ \\
\hline
\end{tabular}

Tabela 2. Administração Direta SES (CAIS, Hospitais, Institutos e Centros de Referência) Fonte: Portal Financeiro do Gestor - GCOF/SES - 13 abr.2020. Disponível em: http://www.portalfinanceirodogestor.saude.sp.gov.brl. Adaptada pelo autor.

Apesar dos altos custos de manutenção da prestação pública, há uma carência de análise e de medidas de desempenho organizacional entre o modelo de prestação privado, 
financiado por repasses de recursos públicos, e o modelo público, fato essencial para orientar e propor alterações que resultem numa melhor eficiência.

É preciso analisar se essas formas de privatização e expansão do setor privado de saúde, respaldada pelo próprio Estado brasileiro e seus níveis de governo, não se configuram num pro $c$ cesso maior, que vem na tendência internacional de desmonte dos sistemas de proteção social, com utilização dos contratos de gestão saúde pública tão somente como um recurso administrativo mais flexível posto à disposição da Administração Pública em razão da não submissão ao regime jurídico de direito, que impõe "travas" legais para contratação e gestão dos recursos humanos e financeiros. Tal fato, por si só, não pode servir como justificativa para a utilização do modelo de gestão de serviços de saúde por meio da descentralização, em particular às entidades do terceiro setor como as OSs.

Daí porque mostra-se relevante o estabelecimento de uma agenda de estudos sobre os impactos das mudanças estratégicas do papel a ser desempenhado pelo Estado na efetivação do direito à saúde e sobre a eficiência dos modelos de prestação de serviços existentes.

A ausência de informações relativas ao desempenho organizacional das parcerias com entidades privadas alimenta a tese de que a contratação com entidades privadas e do terceiro setor se dão para possibilitar a fuga dos preceitos constitucionais da licitação e do concurso público que balizam a Administração Pública e não estas entidades, reforçando a crítica quanto a uma aplicação indiscriminada do direito privado como forma de escapar dos controles de Direito Administrativo (Alcântara, 2009:52), e da restrição da proteção social garantida constitucionalmente por meio do aumento dos processos de privatização.

Por sua vez, de acordo com o Global Health Expenditure Database (GHED), da Organização Mundial da Saúde (OMS), quando comparamos o financiamento governamental em saúde e as despesas per capita do Brasil em saúde em relação a outras nações que possuem um sistema universal de saúde no período de 2011 a 2017, vemos que o Brasil possui gasto em saúde pública inferior a Canadá, Reino Unido, Suécia, Dinamarca, Portugal, resultado do desfinanciamento crônico do SUS:

\begin{tabular}{|c|c|c|c|c|c|c|c|}
\hline Países & $\mathbf{2 0 1 1}$ & $\mathbf{2 0 1 2}$ & $\mathbf{2 0 1 3}$ & $\mathbf{2 0 1 4}$ & $\mathbf{2 0 1 5}$ & $\mathbf{2 0 1 6}$ & $\mathbf{2 0 1 7}$ \\
\hline Brasil & 456 & 412 & 434 & 445 & 333 & 342 & 389 \\
\hline Canadá & 3.990 & 4.031 & 3.983 & 3.785 & 3.387 & 3.339 & 3.505 \\
\hline Cuba & 616 & 518 & 618 & 773 & 881 & 872 & 883 \\
\hline Dinamarca & 5.252 & 5.042 & 5.255 & 5.372 & 4.604 & 4.682 & 4.874 \\
\hline Portugal & 1.493 & 1.257 & 1.310 & 1.312 & 1.140 & 1.194 & 1.264 \\
\hline Espanha & 2.135 & 1.868 & 1.867 & 1.881 & 1.675 & 1.700 & 1.770 \\
\hline Suécia & 5.363 & 5.244 & 5.606 & 5.526 & 4.686 & 4.759 & 4.942 \\
\hline Reino Unido & 2.951 & 2.952 & 3.363 & 3.682 & 3.460 & 3.160 & 3.064 \\
\hline
\end{tabular}

Tabela 3. Despesas governamentais em saúde per capita em US\$ - países com sistema universal de saúde Fonte: Organização Mundial de Saúde - 25 jun. 2020. Disponível em: https://apps.who.int/nha/databasel Select/Indicators/en. 
Mesmo no caso da Espanha, que possui um sistema dual que admite a participação pública e privada, o investimento público é maior do que o privado, contrariamente ao caso brasileiro.

Ainda, o financiamento governamental entre os países que possuem sistema universal de saúde e o gasto com saúde privada no mesmo período de 2011 a 2017, pudemos perceber que a porcentagem do gasto público com as despesas em saúde no Brasil variou de $45 \%$ (quarenta e cinco por cento) para $42 \%$ (quarenta e dois por cento) ${ }^{12}$

Porém, o recente cenário enfrentado pelas nações do mundo e pelo Brasil com a COVID-19 serviu para demonstrar que a prestação dos serviços públicos de saúde pelo privado jamais será capaz de dar conta de um atendimento médico da forma como exigido, pelo fato de não ser organizada de maneira estrutural e permanente como o SUS.

Esta emergência internacional mostrou que a saúde não deve ser vista como um antônimo de doença, em que a oferta e o acesso a serviços médicos e hospitalares por si só bastariam para garanti-la: deve ser compreendida também em seu contexto econômico e social, reconhecendo que existem outros fatores que condicionam o Estado de Bem Estar e de saúde dos indivíduos.

Carecemos, na verdade, de uma melhor governança sanitária entre público e privado, por meio de um melhor entrelaçamento entre os governos e atores sociais que possibilitem guiar as comunidades, países ou grupos de países na busca da saúde como um elemento essencial de bem-estar, utilizando abordagens que envolvam todo o governo e toda a sociedade (Kickbusch e Gleicher, 2012:1), por meio de processos que propiciem melhores decisões em relação a políticas públicas no território nacional brasileiro (Lima et. al., 2019:2).

Como assenta Oliveira (2015:82), o estabelecimento de relações eficientes dos atores e agentes públicos com o mercado e com a sociedade é essencial para a boa prestação dos serviços referências de saúde, de modo a sedimentar uma governança sanitária que possibilite que o complexo e policêntrico sistema de saúde brasileiro consiga alcançar níveis ótimos de realização das ações e prestações dos serviços a ele imanentes, conquistando a efetividade do direito à saúde.

Reconhecemos assim a necessidade do fortalecimento da figura do Estado prestador de serviços e fomentador de pesquisas e também uma melhor governança sanitária, e não simplesmente de um modelo que somente estimula, ajuda e subsidia a iniciativa privada e relega a ele um papel de mero "regulador" e de árbitro ativo das relações sociais.

\section{Conclusão}

Como Estado de bem estar social, o Brasil caracteriza-se como "Estado de direito inclusivo", donde o ente estatal assume obrigações perante os cidadãos e procura dialogar com os anseios dos mais diferentes conjuntos de atores sociais. Nesse contexto, os direitos sociais insculpidos na Constituição Federal representam compromissos da comunidade e não trunfos, normas de ação e não de controle, ainda que se admita que tais direitos possam estar sujeitos a um juízo de ponderação em virtude da escassez de recursos do Estado (Coutinho, 2014:87-88). 
De acordo com Marques Neto (2005:112), cabe ao Estado, na esfera de pública de prestação de serviços públicos de saúde, garantir-Ihes a existência e provê-los, seja mediante execução direta ou mediante participação complementar da iniciativa privada. Daí porque o fomento estatal a entidades privadas sem fins lucrativos para prestarem serviços de relevância pública (setor público não estatal) é constitucionalmente permitido e incentivado, mediante um modelo descentralizado baseado nos contratos de gestão.

Mas observa-se na prática que a redefinição do papel do Estado está a menos relacionada à dimensão de organização do Estado e da Administração Pública em si e mais à desvinculação receitas para o setor da saúde. Ao que nos parece, a gestão por meio de contratualizações com entes privados está longe de avançar para um sistema de saúde tal como está descrito e previsto na Constituição de 1988, com acesso universal, atendimento integral e, especialmente, com políticas de prevenção de agravos e promoção da saúde (Pilotto e Junqueira, 2017:557). A relação entre a proteção social e pobreza é evidente, realçando o papel de destaque exercido pelos sistemas públicos e universais de saúde no amparo aos pobres e alívio de suas péssimas condições de existência. Ainda é possível verificar que modelos de maiores performances em termos de saúde são aqueles que consagram a universalização da saúde pública e nos quais a proteção social exerce papel crucial, conferindo-Ihes legitimidade para atuar frente à atenção básica de saúde, à vigilância sanitária, aos hospitais públicos e nas pesquisas científicas desenvolvidas pelas universidades, na maioria também públicas (Sousa et al., 2020:66). Para Barbosa (1996:91), demonstram o quanto é fundamental que a saúde se expresse enquanto questão de Estado em seu aspecto estrutural e que isto se manifeste pela maior capacidade de intervenção/regulação estatal e pela definição das prioridades sanitárias e das condições para viabilizá-las.

Este aspecto foi bem ilustrado pelas recentes crises e emergências mundiais, que escancararam a fragilidade de um sistema neoliberal, no qual estão ausentes a garantia de qualidade de vida da população e dos direitos básicos que deveriam pautar qualquer Estado de Direito (Machado e Casanova, 2020:150). O cenário delas decorrente corroborou a importância do SUS, sua necessidade de ser universal e igualitário, demonstrando o papel do federalismo cooperativo na área social em detrimento da quebra do pacto social.

Doutro giro, há necessidade de estabelecermos uma melhor governança sanitária, por meio de um processo de escolha do(s) melhor(es) modelo(s) de gestão para a execução das ações e da prestação dos serviços que seja(m) adequado(s) e motivado(s), com a necessária conjugação dos recursos materiais e humanos dos órgãos públicos coordenadores do sistema com aqueles recursos e potenciais existentes no mercado e na sociedade civil, em uma visão colaborativa e parceirizada (Oliveira, 2015:82).Ao que parece, o debate sobre a melhor forma de implementação do SUS e sobre qual deve ser o modelo de gestão a ser utilizado ainda suscita sucessivas investigações, demonstrando que o problema da saúde pública no Brasil está longe de ser resolvido. 


\section{REFERÊNCIAS BIBLIOGRÁFICAS}

- Aith, F.M.A (2014). Direito à saúde e democracia sanitária: experiências brasileiras. Revista de Direito Sanitário. São Paulo v.15 n.3, p. 85-90, 2014. Disponível em: http://www. revistas.usp.br/rdisan/article/view/97328.

- Barbosa. P.R. (1996). Gestão de Hospitais Públicos: maior autonomia gerencial, melhor performance organizacional com apoio em contratos de gestão. Revista do Serviço Público, Brasília, n. 120, v.2, p. 67-97. Disponível em: https://revista.enap.gov.br/index.php/ RSP/issue/view/83.

- Barroso, L.R. (2005). Neoconstitucionalismo e constitucionalização do Direito (O triunfo tardio do direito constitucional no Brasil). Revista de Direito Administrativo, Rio de Janeiro, v. 240, p. 1-42. Disponível em: http://bibliotecadigital.fgv.br/ojs/index.php/rda/article/ view/43618.

- Binenbojm. G. (2008). A constitucionalização do direito administrativo no Brasil: um inventário de avanços e retrocessos. Revista Eletrônica sobre a Reforma do Estado (RERE), Salvador, Instituto de Direito Público, n. 13, p. 1-44. Disponível em: http://www.direitodoestado.com.br/codrevista.asp?cod=262

- Brasil. Lei Complementar n. 101, de 4 de maio de 2000. Estabelece normas de finanças públicas voltadas para a responsabilidade na gestão fiscal e dá outras providências. Diário Oficial da União, Brasília, DF, 05 mai.2000, Seção 1, p. 1. Disponível em: http://www. planalto.gov.br/ccivil_03/leis/lcp/lcp101.htm.

- Brasil. Emenda Constitucional n 19, de 04 de junho de 1998. Modifica o regime e dispõe sobre princípios e normas da Administração Pública, servidores e agentes políticos, controle de despesas e finanças públicas e custeio de atividades a cargo do Distrito Federal, e dá outras providências. Diário Oficial da União, Brasília, DF, 5 jun. 1998, Seção 1, p. 1. Disponível em: http://www.planalto.gov.br/ccivil_03/Constituicao/Emendas/Emc/emc19.htm - Brasil. Emenda Constitucional n 86, de 17 de março de 2015. Altera os arts. 165, 166 e 198 da Constituição Federal, para tornar obrigatória a execução da programação orçamentária que especifica. Diário Oficial da União, Brasília, DF, 18 mar. 2015, Seção 1, p 1. Disponível em: http://www.planalto.gov.br/ccivil_03/constituicao/Emendas/Emc/emc86. htm. Acesso em: 09 jun.2020.

- Brasil. Emenda Constitucional n 95, de 15 de dezembro de 2016. Altera o Ato das Disposições Constitucionais Transitórias, para instituir o Novo Regime Fiscal, e dá outras providências. Diário Oficial da União, Brasília, DF, 16 dez. 2016, Seção 1, p 2. Disponível em: http://www.planalto.gov.br/ccivil_03/constituicao/Emendas/Emc/emc95.htm.

- Brasil. Lei n. 8.080, de 19 de setembro de 1990. Dispõe sobre as condições para a promoção, proteção e recuperação da saúde, a organização e o funcionamento dos serviços correspondentes e dá outras providências. Diário Oficial da União, Brasília, DF, 20 set. 1990, p. 018055. Disponível em: http://www.planalto.gov.br/ccivil_03/leis/L8080.htm.

- Brasil. Lei n. 9.637, de 15 de maio de 1998. Dispõe sobre a qualificação de entidades como organizações sociais, a criação do Programa Nacional de Publicização, a extinção dos órgãos e entidades que menciona e a absorção de suas atividades por organizações sociais, e dá outras providências. Diário Oficial da União. Brasília, DF, 18 mai.1998, p. 8, Seção 1, retificado em 25 mai. 1998, p. 1, Seção 1. Disponível em: http://www.planalto. gov.br/ccivil_03/leis/l9637.htm.

- Buss. P.M. et al. Governança em saúde e ambiente para o desenvolvimento sustentável. Ciência \& Saúde Coletiva, vol. 17, n.6, p. 1479-1491. Disponível em: https://www.scielo. $\mathrm{br/j/csc/a/G34H9bB9CN6bSYtVZ45S7Rp/?lang=pt.}$

- Coutinho. L. P. (2014). Os direitos sociais como compromissos. e-Pública, Lisboa, 
v. 1, n. 3, p. 86-98. Disponível em http://www.scielo.mec.pt/scielo.php?script=sci_ arttext\&pid=S2183-184X2014000300006\&lng=pt\&nrm=iso.

- Giovanella et al (2018). Sistema universal de saúde e cobertura universal: desvendando pressupostos e estratégias. Ciências da Saúde Coletiva, Rio de Janeiro, v. 23, n. 6, p. 17631776. Disponível em: http://www.scielo.br/scielo.php?script=sci_arttext\&pid=S1413$81232018000601763 \&$ Ing $=e n \& n r m=i s o>$.

- Kickbusch. I.Gleicher. D. Governance for health in the 21st century. Denmark: World Health Organization, 2012. Disponível: http://www.euro.who.int/en/what-we-publish/ abstracts/governance-for-health-in-the-21st-century.

- Lima. L.D. et al. Arranjos regionais de governança do Sistema Único de Saúde: diversidade de prestadores e desigualdade espacial na provisão de serviços. Cadernos de Saúde Pública, v. 35, supl. 2. Disponível em: https://www.scielo.br/j/csp/a/Hgmr8CynXVf6f8J5P Bs3XFs/?lang=pt.

- Louvison, M.C.P (2019). Regionalização dos sistemas de saúde como resposta às desigualdades territoriais: um debate necessário. Caderno de Saúde Pública, Rio de janeiro, v. 35, supl. 2, p. 1-3 Disponível em: http://www.scielo.br/scielo.php?script=sci_ arttext\&pid=S0102-311X2019000800404\&Ing=en\&nrm=iso.

- Machado. F.A.M. Casanova K.T.C. (2020). Neoliberalismo em tempo de Covid-19. In: Capitalismo e a Covid-19: um debate urgente. Castro. D. Dal Seno. Pochman. M. (Orgs.). São Paulo, p. 149-156. Disponível em: http://abet-trabalho.org.br/wp-content/ uploads/2020/05/LIVRO.CapitalismoxCovid19.pdf.

- Marques Neto. F.de A.M. (2005). Público e Privado no Setor da Saúde. Revista de Direito Público da Economia - RDPE, Belo Horizonte, n. 9, p. 105-151.

- Meniccucci. T. M. G. Público e privado na política de assistência à saúde no Brasil: atores, processos e trajetória. Rio de Janeiro: Fiocruz, 2007.

- Ocké-Reis. C. Carvalho S. D. (2009). Uma crítica à privatização do sistema de saúde brasileiro: pela constituição de um modelo de proteção social público de atenção à saúde. Revista Saúde em Debate, Rio de Janeiro, vol. 33, n. 81, p. 72-79. Disponível em: http://docvirt.com/asp/acervo_cebes.asp?Bib=SAUDEDEBATE\&PASTA=V.33\%2C+N.81++ jan\&pesq $=\& x=55 \& y=0$

- Oliveira. G. J. (2015). Efetivação do Direito à Saúde: ampliação do debate e renovação da agenda. Revista de Direito Sanitário, São Paulo, v. 16, vol. 1, p. 76-82. Disponível em: https://www.revistas.usp.br/rdisan/article/view/100024.

- Oliveira. G. J. (2008). Contrato de Gestão. São Paulo: Editora Revista dos Tribunais.

- Palma. J. B. (2015). Sanção e acordo na Administração Pública. São Paulo: Malheiros.

- Pilotto. B. S. Junqueira. V. (2017). Organizações Sociais do setor de saúde no estado de São Paulo: avanços e limites do controle externo. Serviço Social e Sociedade, São Paulo, n. 130, p. 547-563. Disponível em http://www.scielo.br/scielo.php?script=sci_ arttext\&pid=S0101-66282017000300547\&lng=pt\&nrm=iso.

- Santos. L. (2010). Administração pública e a gestão da saúde. In: Santos. N. R. Amarante. P. D. de C. (Orgs.). Gestão Pública e Relação Público Privado na Saúde. São Paulo: Centro Brasileiro de Estudos de Saúde (CEBES), p. 68-100.

- São Paulo. Secretaria Estadual de Saúde. Portal Financeiro do Gestor - CGOF/SES. Disponível em http://www.portalfinanceirodogestor.saude.sp.gov.br/.

- Scheffer. M. Aith. (2016). Sistema de Saúde Brasileiro. In: Clínica Médica, vol. 1. São Paulo: Manole.

- Silva. J.A. (2010). Curso de Direito Constitucional Positivo. 33a edição, revista e atualizada. São Paulo: Editora Malheiros.

- Sousa. A. F.J.P. Briones. F.M.A. Macambira. J. (2020). Saúde Pública e sua importância 
na luta contra a pobreza e a exclusão social. In: Capitalismo e a Covid-19: um debate urgente. D. Dal Seno. Pochman. M. (Orgs.). São Paulo, p. 65-73. Disponível em: http://abettrabalho.org.br/wp-content/uploads/2020/05/LIVRO.CapitalismoxCovid19.pdf.

- Sundfeld. C.A. (2010). Fundamentos de Direito Público. $5^{a}$. edição, $3^{a}$ tiragem. São Paulo. Editora Malheiros.

- Yarid. A. T. (2009). Algumas reflexões sobre as políticas de saúde no Brasil. In: Livianu. R. (Org.). Justiça, Cidadania e Democracia. Rio de Janeiro: Centro Edelstein de Pesquisa Social. Disponível em: http://books.scielo.org/.

-Who - World Health Organization. Global Health Expenditure Database. Disponível em: https://apps.who.int/nha/database/ViewData/Indicators/en 